\title{
EFEKTIVITAS PEMBELAJARAN DITINJAU DARI SUPERVISI AKADEMIK KEPALA SEKOLAH DAN BUDAYA SEKOLAH
}

\author{
Dewi Nurpuspitasari ${ }^{1}$, Sumardi $^{2}$, Rais Hidayat ${ }^{2}$, Sutji Harijanto ${ }^{2}$ \\ ${ }^{1}$ Guru SDN Serang Baru, Bekasi Jawa Barat \\ ${ }^{2}$ Program Pascasarjana Universitas Pakuan \\ Email: pasca@unpak.ac.id
}

\begin{abstract}
The effectiveness of learning is the key to success in education. This reserch aims to improve the effectiveness of teacher learning through the search for the correlation the academic principals and school culture. This reserach used a survey method with correlational research techniques. This research was carried out on teachers in Public Elementary Schools in the District of Serang Baru District, Bekasi Regency. The sample of this reseach amounted 124 of 179 populations. Data collection in this reserach uses the questionnaires as instruments. The results of this research are: 1) there was a very significant positive correlation the academic supervision and the effectiveness of teacher learning, with the correlation coefficient $r=0.508 ; 2)$ there is a very significant positive correlation school culture and the effectiveness of teacher learning with the correlation coefficient $r=0.438$; and (3) there is a very significant positive correlation school principals' academic supervision and school culture on effectiveness of learning with the correlation coefficient $r$ $=0.6331$. Based on those results that the effectiveness of teacher learning will be maximized, if there is an effort to increase the school supervisor's academic supervision and school culture.
\end{abstract}

Key words: Academic supervision, school culture and learning effectiveness.

\begin{abstract}
ABSTRAK
Efektivitas pembelajaran merupakan kunci keberhasilan dalam pendidikan. Penelitian ini bertujuan untuk memperbaiki efektivitas pembelajaran guru melalui pencarian hubungan suverpisi akademik kepala sekolah dan budaya sekolah. Penelitian ini menggunakan metode survey dengan teknik korelasional penelitian, dengan rancangan penelitian korelasional. Penelitian ini dilaksanakan pada guru di Sekolah Dasar Negeri yang berada di Wilayah Kecamatan Serang Baru Kabupaten Bekasi yang berjumlah 21 sekolah. Sampel diambil secara random proporsional yang berjumlah 124 dari 179 populasi. Pengumpulan data dalam penelitian ini menggunakan kuisioner atau angket sebagai instrumen. Hasil penelitian menunjukkan bahwa: 1) terdapat hubungan positif yang sangat signifikan supervisi akademik dengan efektivitas pembelajaran guru, dengan skor koefisien korelasi $r_{y 1}=0,508 ; 2$ ) terdapat hubungan positif yang sangat signifikan antara budaya sekolah dengan efektivitas pembelajaran guru, karena diperoleh besarnya skor koefisien korelasi $\mathrm{r}_{\mathrm{y} 2}=0,438$; dan (3) terdapat hubungan positif yang sangat signifikan antara supervisi akademik kepala sekolah dan budaya sekolah secara bersama-sama dengan efektivitas pembelajaran guru. skor koefisien korelasi $r_{y 12}=0,6331$. Berdasarkan hasil penelitian bahwa efektivitas pembelajaran guru akan maksimal, apabila ada upaya untuk meningkatkan supervisi akademik kepala sekolah dan budaya sekolah.
\end{abstract}

Kata kunci: supervisi akademik, budaya sekolah, dan efektivitas pembelajaran 


\section{PENDAHULUAN}

Tugas mengajar guru ditetapkan berdasarkan keahlian dan kompetensi guru. Sebagian guru SD Negeri di Kecamatan Serang Baru Kabupaten Bekasi telah diangkat menjadi pegawai negri sipil dan sebagian sudah bersertifikasi dan berijasah S1 pendidikan. Sebuah pengukuran mengenai sudah tercapainya atau belum sistem pendidikan yang diharapkan dari supervisi akademik kepala sekolah dan budaya sekolah pada akhirnya akan berdampak pada efektivitas pembelajaran SDN di Kecamatan Serang Baru Kabupaten Bekasi.

Efektivitas pembelajaran dapat dipengaruhi oleh beberapa faktor, selain supervisi akademik kepala sekolah sebagai pembina untuk meningkatkan proses pembelajaran juga, dipengaruhi oleh banyaknya faktor lain seperti budaya sekolah, kepemimpinan, kepuasan kerja, lingkungan sekolah, iklim ornanisasi sekolah, juga faktor-faktor yang lain. Mencermati uraian tersebut, maka perlu adanya penelitian pada sumber masalahnya yaitu bagaimana korelasi antara supervisi akademik kepala sekolah dan budaya sekolah dalam peningkatan efektivitas pembelajaran, khususnya guru Sekolah Dasar Negeri di Kecamatan Serang Baru Kabupaten Bekasi

\section{Efektivitas Pembelajaran}

Menurut kajian Popi Sopiatin (2010: h. 24) mengemukakan pendapatnya bahwa agar pembelajaran berlangsung efektif maka guru perlu memahami terlebih dahulu isi/perangkat kurikulum yang terdiri dari: (1) Pedagogik, (2) Material, dan (3) Alat-alat yang digunakan dalam proses belajar mengajar. Artinya bahwa perencanaan pembelajaran, penentuan metode dan media yang tepat, sampai penetapan teknik evaluasi dapat menjadikan pembelajaran efektif dapat berjalan maksimal.

Popham dan Baker (2011: hh.11-12) memaparkan bahwa efektivitas pembelajaran didefinisikan sebagai kesanggupan menimbulkan perubahan-perubahan yang diinginkan pada kemampuan dan persepsi siswa. Indikator-indikatornya antara lain: 1) Menentukan tujuantujuan pembelajaran, 2) Melakukan penilaian pendahuluan untuk mengetahui kesiapan siswa yang berhubungan dengan tujuan-tujuan pembelajaran, 3) Melaksanakan pembelajaran yang menyenangkan dan membantu siswa untuk memahami tujuan pembelajaran yang harus dicapainya, dan 4) Melakukan evaluasi untuk mengetahui pencapaian tujuan yang dicapai siswa.

Menurut teori Jones and Walters (2008:128) efektivitas pembelajaran harus didukung oleh guru kompeten, dimana guru yang kompeten adalah komponen yang menggambarkan system pembelajaran yang efektif dalam hampir seluruh penelitian pada bidang pendidikan. Ciri-ciri guru yang kompeten: 1) Melakukan proses mengajar demi tujuan tertentu, 2) Menetapkan tujuan mengajar berdasarkan tingkat kesulitan yang tepat, 3) Mampu mengawasi dan mengelola materi pelajaran, 4) Mampu memahami prinsip-prinsip pembelajaran, dan 5) Memiliki keinginan untuk terus berkembang

Berlandaskan kajian teori di atas, dapat disintesiskan bahwa yang dimaksud dengan efektivitas pembelajaran adalah upaya pembelajaran yang dilakukan guru yang terfokus kepada hasil yang dicapai peserta didik berupa pemahaman, kecerdasan, ketekunan, kesempatan, dan mutu pembelajaran sehingga memberikan perubahan perilaku positif bagi peserta didik. Efektivitas pembelajaran guru dapat diukur melalui indikator-indikator efektivitas pembelajaran yang akan dijadikan kajian dalam penelitian ini meliputi: 1) Penerapan model pembelajaran di kelas, 2) Penggunaan media pembelajaran di kelas, 3) Pengelolaan kelas, 4) Evaluasi pengajaran, dan 5) Interaksi antara guru dengan siswa.

\section{Supervisi Akademik}

Menurut Rue dan Byars (2007:134) memaparkan bahwa supervisi adalah ujung tombak manajemen dalam organisasi dan melalui pemberian dorongan kepada anggota 
organisasi untuk memberikan kontribusi positif terhadap tujuan organisasi yang ingin dicapai. Faktor-faktor yang mempengaruhi supervisi adalah: 1) Organisasi (organizin7), 2) pegawai (staffin7), 3) Kepemimpinan (leadership), dan 4) Pengawasan (controllin7).

Paparan Mulyasa (2003:76) menyatakan bahwa supervisi merupakan suatu proses yang dirancang secara khusus untuk membantu para guru dan supervisor mempelajari tugas sehari-hari di sekolah, agar dapat menggunakan pengetahuan dan kemampuannya untuk memberikan layanan yang lebih baik pada orang tua peserta didik dan sekolah, serta berupaya menjadikan sekolah sebagai masyarakat belajar yang lebih efektif. Faktor-faktor yang mempengaruhi supervise yaitu: (1) hubungan konsultatif, kolegial, dan bukan hirarkis, (2) dilaksanakan secara demokratis, (3) berpusat pada tenaga kependidikan (guru), (4) dilakukan berdasarkan kebutuhan tenaga pendidik (guru), dan (5) merupakan bantuan professional.

Pendapat Sergiovanni dan Starrat (2009:122) mengemukakan: "the purpose of supervision is to help increase the opportunity ang the capacity of school to contribute more effectively to students' academic success". Tujuan supervisi adalah untuk menambah kesempatan dan kapasitas sekolah untuk membantu bidang akademik siswa lebih efektif. Kepala sekolah memfasilitasi guru dan membantu bagaimana guru mengajar dengan baik. Faktor-faktornya meliputi: 1) Kapasitas pelajaran sekolah, 2) Kualitas pelajaran, 3) Komitmen siswa dan 4) Partisipasinya dalam belajar

Mengacu pada kajian teori di atas, dapat disintesiskan bahwa yang dimaksud dengan supervisi akademik kepala sekolah adalah kegiatan membantu guru secara langsung dalam mengelola proses pembelajaran untuk mencapai tujuan akademik, bahan-bahan pengajaran, metode mengajar, dan penilaian pengajaran untuk memberikan kontribusi positif terhadap pencapaian tujuan sekolah, adapun Indikator-indikator dari supervisi kepala sekolah adalah: 1) Pengarahan, 2) Membantu memecahkan masalah guru, 3) Memberikan petunjuk pelaksanaan kerja, 4) Melaksanakan pengawasan, 5) Menciptakan hubungan antarpribadi, dan 6) Penilaian hasil kerja.

\section{Budaya Sekolah}

Luthans (2011:7) menyatakan bahwa budaya organisasi adalah pemahaman terhadap nilai-nilai dan norma-norma yang penting dalam organisasi yang mengarahkan perilaku anggota organisasi. Dimensi budaya organisasi yaitu : 1) pola perilaku nyata anggota organisasi, 2) norma-norma dan standard perilaku dalam bekerja, 3) nilai-nilai terpenting (dominan) yang dipahami bersama, 4) peraturan-peraturan yang menjadi pedoman bagi anggota, dan 5) iklim organisasi yaitu suasana yang dirasakan anggota dalam kehidupan di dalam organisasi

Good dalam Adi Kurnia dan Bambang Qomaruzzaman (2012:24-25) menyatakan bahwa budaya sekolah merupakan jaringan kompleks dari berbagai interaksi aktor dalam sekolah yang dimanifestasikan dalam tradisi dan ritual yang dibangun di antara guru, murid, orang tua, administrator untuk menghadapi berbagai tantangan dan mencapai tujuan. Elemenelemen budaya sekolah adalah: 1) Visi misi dan tujuan: nilai, kepercayaan, norma dan asumsi, 2) Ritual dan seremoni, 3) Sejarah dan cerita, 4) Manusia dan hubungan, dan 5) Arsitektur, simbol dan artifak.

Muhaimin (2010:48-55) menjelaskan bahwa budaya sekolah/madrasah merupakan sesuatu yang dibangun dari hasil pertemuan antara nilai - nilai (values) yang dianut oleh kepala sekolah/madrasah sebagai pemimpin dengan nilai - nilai yang dianut oleh guru - guru dan para karyawan yang ada dalam sekolah/madrasah tersebut, dengan aspek-aspeknya antara lain: 1) Inovatif, adaptif, bekerja keras, dan peduli terhadap orang lain, 2) Disiplin, jujur, hubungan yang sederhana antar orang dan bagian, dan berwawasan luas, 3) Inisiatif, kebersamaan, tanggung jawab, rasa memiliki, dan komitmen terhadap lembaga, dan 4) Kerja sama, saling pengertian, semangat persatuan, taat atas memotivasi, dan membimbing. 
Berdasarkan deskripsi teoritis di atas dapat disimpulkan bahwa budaya sekolah adalah suatu sistem nilai, kebiasaan dalam suatu sekolah yang dibangun dari hasil suatu pertemuan antara nilai-nilai yang dianut oleh kepala sekolah dengan nilai-nilai yang dianut oleh guru dan tenaga kependidikkan dalam sekolah tersebut. Indikator budaya sekolah antara lain: 1) Peraturan yang dijadikan pedoman penyelesaian masalah, 2) Norma-norma yang disepakati anggota, 3) Adaptasi terhadap lingkungan sekolah, 4) Mendorong inovasi, dan 5) Hubungan dalam organisasi sekolah.

\section{METODE PENELITIAN}

Peneltian ini bertujuan untuk mendeskripsikan pengaruh dari variabel supervisi kepala sekolah dan budaya sekolah dengan efektivitas pembelajaran pada guru SDN di Kecamatan Serang Baru Kabupaten Bekasi. Metode penelitian yang digunakan adalah metode survey dengan pendekatan korelasional. Dengan menggunakan metode ini diharapkan dapat menyelesaikan permasalahan dalam lembaga pendidikan yang berkenaan dengan efektivitas pembelajaran. Dalam penelitian ini diharapkan dapat diketahui pula seberapa besar hubungan antara variabel-variabel tersebut baik sendiri-sendiri maupun secara bersama-sama. Hubungan antara variabel bebas dan variabel terikat digambarkan dalam bentuk konstelasi penelitian seperti pada gambar berikut.

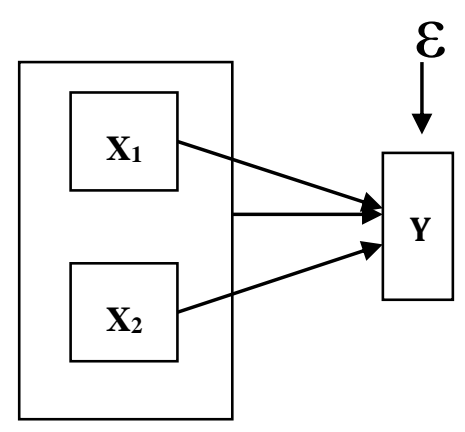

Penelitian ini dilaksanakan di Sekolah Dasar Negeri yang berada di Wilayah Kecamatan Serang Baru Kabupaten Bekasi yang berjumlah 21 sekolah. Sampel diambil secara random proporsional yang berjumlah 124 dari 179 populasi. Pengumpulan data dalam penelitian ini menggunakan kuisioner atau angket sebagai instrumen. Uji coba instrumen dilakukan melalui teknik korelasi Product Moment Pearson. Uji reliabilitas instrumen penelitian menggunakan perhitungan Alpha Cronbach,. Sedangkan analisis data menggunakan statistik inferensial dengan menggunakan uji analisis varian dan regresi.

\section{HASIL DAN PEMBAHASAN}

\section{Hubungan Antara Supervisi Akademik Kepala Sekolah Dengan Efektivitas Pembelajaran}

Supervisi akademik kepala sekolah adalah kegiatan membantu guru secara langsung dalam mengelola proses pembelajaran untuk mencapai tujuan akademik. Efektivitas pembelajaran guru adalah upaya pembelajaran yang dilakukan guru yang terfokus kepada hasil yang dicapai peserta didik berupa pemahaman, kecerdasan, ketekunan, kesempatan, dan mutu pembelajaran sehingga memberikan perubahan perilaku positif bagi peserta didik.

Berdasarkan hasil perhitungan koefisien korelasi antara supervisi akademik kepala sekolah $\left(\mathrm{X}_{1}\right)$ dengan efektivitas pembelajaran guru $(\mathrm{Y})$ dapat disimpulkan bahwa terdapat hubungan positif yang sangat signifikan antara supervisi akademik kepala sekolah dengan 
efektivitas pembelajaran guru (Y), karena diperoleh besarnya skor koefisien korelasi $\mathrm{r}_{\mathrm{y} 1}=$ 0,5086 .

Kontribusi supervisi akademik kepala sekolah $\left(\mathrm{X}_{1}\right)$ dalam menerangkan efektivitas pembelajaran guru (Y) melalui skor koefisien determinasi $\mathrm{r}_{\mathrm{y} 1}{ }^{2}=0,2587(25,87 \%)$ karena diperoleh skor $t_{\text {hitung }}=5,336>\mathrm{t}_{\text {tabel }}=1,66$ pada taraf signifikan 0,05. Demikian, menunjukkan $25,87 \%$ efektivitas pembelajaran guru (Y) dapat diterangkan oleh supervisi akademik kepala sekolah. (Lampiran 8: 198-203).

Hasil penelitian menunjukkan terdapat hubungan positif yang sangat signifikan antara supervisi akademik dengan efektivitas pembelajaran guru (Y) dan hubungan tersebut merupakan hubungan fungsional yang memiliki arti bahwa peningkatan peran supervisi akademik kepala sekolah dapat meningkatkan efektivitas pembelajaran guru (Y). Hal ini didukung oleh pendapat Jones dalam Mulyasa (2003: h.155) yang menyatakan supervisi merupakan bagian yang tidak terpisahkan dari seluruh proses administrasi pendidikan yang ditujukan terutama untuk mengembangkan efektivitas kinerja personalia sekolah yang berhubungan tugas-tugas utama pendidikan. Mengacu pada teori tersebut tentang supervisi akademik kepala sekolah menitik beratkan pengamatan supervisor pada masalah-masalah akademik, yaitu hal-hal yang langsung berada dalam lingkungan kegiatan pembelajaran pada waktu siswa sedang dalam proses pembelajaran. Artinya supervisi akademik merupakan serangkaian kegiatan pembinaan membantu guru dalam meningkatkan kualitas mengajarnya yang berimplikasi pada meningkatnya hasil belajar peserta didik, hal ini cenderung bahwa supervisi akademik yang benar akan meningkatkan efektivitas pembelajaran guru.

Dengan demikian penelitian ini memdukung penelitian sebelumnya oleh SCIRJ oleh Roseline U. Chidobi (2015) dengan judul "Supervision As a Key for Effectiveness Teaching and Learning in Enugu State of Nigeria Secondary School: Relevance and Chellenges" menunjukkan terdapat hubungan positif yang signifikan antara supervisi akademik kepala sekolah dengan efektivitas pembelajaran, dengan koefisien korelasi (r) sebesar 0,333 pada $\alpha$ $=0,05$. Berarti, semakin tinggi supervisi akademik kepala sekolah guru, akan semakin tinggi pula efektivitas pembelajaran guru.

\section{Hubungan Antara Budaya Sekolah dengan Efektivitas Pembelajaran}

Budaya sekolah adalah suatu sistem nilai, kebiasaan dalam suatu sekolah yang dibangun dari hasil suatu pertemuan antara nilai-nilai yang dianut oleh kepala sekolah dengan nilai-nilai yang dianut oleh guru dan tenaga kependidikkan dalam sekolah tersebut.

Efektivitas pembelajaran guru adalah upaya pembelajaran yang dilakukan guru yang terfokus kepada hasil yang dicapai peserta didik berupa pemahaman, kecerdasan, ketekunan, kesempatan, dan mutu pembelajaran sehingga memberikan perubahan perilaku positif bagi peserta didik.

Berdasarkan hasil perhitungan koefisien korelasi antara budaya sekolah $\left(\mathrm{X}_{2}\right)$ dengan Efektivitas pembelajaran guru (Y) dapat disimpulkan bahwa terdapat hubungan positif yang sangat signifikan antara Budaya sekolah dengan efektivitas pembelajaran guru (Y), karena diperoleh besarnya skor koefisien korelasi $\mathrm{r}_{\mathrm{y} 2}=0,4389$. Hal ini terlihat dari skor $\mathrm{F}_{\text {hitung }} 10,02$ $>\mathrm{F}_{\text {tabel }}$ 3,92 pada taraf signifikan 0,05. Persamaan regresi tersebut dapat digunakan untuk memprediksi skor efektivitas pembelajaran guru (Y) melalui skor budaya sekolah (X2).

Kontribusi budaya sekolah $\left(\mathrm{X}_{2}\right)$ dalam menerangkan efektivitas pembelajaran guru (Y) melalui skor koefisien determinasi $\mathrm{r}_{\mathrm{y} 2}{ }^{2}=0,1926(19,26 \%)$ karena diperoleh skor $\mathrm{t}_{\text {hitung }}=$ $4,635>\mathrm{t}_{\text {tabel }}=1,66$ pada taraf signifikan 0,05. Demikian, menunjukkan 36,90\% efektivitas pembelajaran guru dapat diterangkan oleh budaya sekolah.

Hasil penelitian memperlihatkan bahwa terdapat hubungan positif yang sangat signifikan antara budaya sekolah dengan efektivitas pembelajaran guru. Hal ini sesuai dengan Pendapat Dadang Suhardan (2010:121-129) budaya sekolah merupakan variabel 
yang mempengaruhi bagaimana anggota kelompok bertindak dan berperilaku. Budaya sekolah yang dimaksud adalah memiliki aspek-aspek berikut ini: 1) Kolegialitas. Adalah iklim kesejawatan yang menimbulkan rasa saling hormat menghormati dan menghargai sesama profesi kependidikan, 2) Ekperimentasi. Sekolah merupakan tempat yang subur untuk mengadakan percobaan - percobaan kearah menemukan pola kerja yang lebih baik, 3) High Ekspectation. Harapan setiap orang untuk memperoleh prestasi tertinggi yang pernah dicapainya, 4) Trust and Confidence. Kepercayaan dan keyakinan yang kuat merupakan bagian penting yang dianut dalam kehidupan suatu profesi, 5) Tangible Support. Supervisi pada hakekatnya adalah bantuan dan layanan, dukungan dan motivasi, 6) Reaching Out To The Knowledge Base. Sekolah merupakan tempat dimana ilmu pengetahuan dikembangkan secara luas, objektif dan professional, 7) Appreciation and Recognition. Supervisor yng baik adalah supervisor yang dapat memberi pengakuan dan penghargaan atas prestasi guru yang dicapainya, 8) Carring, Celebration and Humor, memberi perhatian, saling menghormati, memuji dan memberi penghargaan atas kebaikan seorang guru disekolah adalah perbuatan yang terpuji, 9) Involvement In decision Making. Keterlibatan staf sekolah dalam mengambil putusan merupakan bagian yang penting dalam pengembangan budaya sekolah, 10) Protection of What's Important. Melindungi dan menjaga kerahasiaan pekerjaan merupakan kultur dan tradisi di sekolah, 11) Tradisi. Memelihara tradisi yang sudah berjalan lama dan dianggap baik adalah budaya dalam lingkungan sekolah, dan 12) Honest, Open Communication. kejujuran dan keterbukaan dilingkungan sekolah memang semestinya terpelihara.

Berdasarkan hasil penelitian di atas tentunya telah mendukung penelitian sebelumnya yang dilaksanakan oleh Rosfairil (2011: h. 61) dengan judul "Hubungan antara Kepemimpinan dan Budaya sekolah terhadap Efektivitas Pembelajaran pada SMA Negeri”, menunjukan terdapat hubungan positif yang signifikan antara budaya sekolah dengan efektivitas pembelajaran. Kekuatan hubungan antara keduanya ditunjukan dengan koefisien (r) sebesar 0,734 dan koefisien determinasi $\left(\mathrm{r}^{2}\right)$ sebesar 0,539. Hubungan antara budaya sekolah dengan efektivitas pembelajaran ditunjukan melalui garis regresi $\bar{Y}=29,832+$ $0,476 \mathrm{X}_{2}$ hasil penelitian tersebut menyimpulkan bahwa budaya organisasi dapat mempengaruhi efektivitas pembelajaran sebesar $48,9 \%$.

\section{Hubungan antara supervisi akademik kepala sekolah dan budaya sekolah secara bersama-sama dengan efektivitas pembelajaran}

Supervisi akademik kepala sekolah adalah kegiatan membantu guru secara langsung dalam mengelola proses pembelajaran untuk mencapai tujuan akademik.

Budaya sekolah adalah suatu sistem nilai, kebiasaan dalam suatu sekolah yang dibangun dari hasil suatu pertemuan antara nilai-nilai yang dianut oleh kepala sekolah dengan nilai-nilai yang dianut oleh guru dan tenaga kependidikkan dalam sekolah tersebut.

Efektivitas pembelajaran guru adalah upaya pembelajaran yang dilakukan guru yang terfokus kepada hasil yang dicapai peserta didik berupa pemahaman, kecerdasan, ketekunan, kesempatan, dan mutu pembelajaran sehingga memberikan perubahan perilaku positif bagi peserta didik.

Berdasarkan pada hasil penelitian dapat disimpulkan terdapat hubungan positif yang sangat signifikan antara supervisi akademik kepala sekolah $\left(\mathrm{X}_{1}\right)$ dan budaya sekolah $\left(\mathrm{X}_{2}\right)$ secara bersama-sama dengan efektivitas pembelajaran guru (Y). Hasil uji signifikan korelasi ganda terhadap kekuatan hubungan antara supervisi akademik kepala sekolah $\left(\mathrm{X}_{1}\right)$ dan budaya sekolah $\left(\mathrm{X}_{2}\right)$ secara bersama-sama dengan efektivitas pembelajaran guru (Y) diperoleh $\mathrm{r}_{\mathrm{y} 12}=0,6331$.

Hasil uji signifikansi korelasi ganda diperoleh $\mathrm{F}_{\text {hitung }}=40,80$ lebih besar dari $\mathrm{F}_{\text {tabel }}=$ 3,92 pada taraf signifikan 0,05 , maka hipotesis yang diterima adalah $\mathrm{H}_{1}$. Dapat ditarik 
kesimpulkan terdapat hubungan positif yang sangat signifikan antara supervisi akademik kepala sekolah dan budaya sekolah secara bersama-sama dengan efektivitas pembelajaran guru.

Berdasarkan skor koefisien korelasi $\mathrm{r}_{\mathrm{y} 12}=0,6331$ dapat diperoleh skor koefisien determinasi $\mathrm{r}_{\mathrm{y} 12}^{2}=0,4008$ atau 40,08\% kontribusi supervise akademik kepala sekolah dan budaya sekolah secara bersama-sama dalam menerangkan efektivitas pembelajaran guru. Secara teoritik hal ini didukung sesuai dengan pernyataan Jones and Walters (2008:128) efektivitas pemebelajaran harus didukung oleh guru kompeten, dimana guru yang kompeten adalah komponen yang menggambarkan system pembelajaran yang efektif dalam hampir seluruh penelitian pada bidang pendidikan. Ciri-ciri guru yang kompeten: 1) Melakukan proses mengajar demi tujuan tertentu, 2) Menetapkan tujuan mengajar berdasarkan tingkat kesulitan yang tepat, 3) Mampu mengawasi dan mengelola materi pelajaran, 4) Mampu memahami prinsip-prinsip pembelajaran, dan 5) Memiliki keinginan untuk terus berkembang.

Perbedaan aktifitas mendidik dan mengajar berbeda, proses pembelajaran hanya menekankan pada aspek pengetahuan, sehingga ketika siswa telah mengerti dan memahami materi pelajaran yang diajarkan maka pengajaran bisa dikatakan berhasil. Aktivitas mendidik adalah melaksanakan pembinaan sikap dan tingkah laku peserta didik agar mereka menjadi manusia yang baik dan berguna bagi orang tua, masyarakat, nusa, bangsa dan agama. Hal ini lebih cenderung pada aspek emosional, mental-spritual dan tingkah laku. Supaya proses mengajar menjadi efektif guru harus memiliki kompetensi dalam mendidik dan mengajar. Guru dapat memenuhi aspek-aspek tersebut bila di sekolah meningkatkan supervisi akademik kepala sekolah dan budaya sekolah guru secara maksimal.

\section{KESIMPULAN}

Terdapat hubungan positif yang sangat signifikan antara supervisi kepala sekolah dengan efektivitas pembelajaran. Hal tersebut berarti bahwa makin kuat supervisi kepala sekolah mengakibatkan peningkatan efektivitas pembelajaran. Oleh karena itu untuk meningkatkan efektivitas pembelajaran, sekolah harus mengoptimalkan kegiatan supervisi kepala sekolah.

Terdapat hubungan positif yang sangat signifikan antara budaya sekolah dengan efektivitas pembelajaran. Hal tersebut berarti bahwa makin kuat budaya sekolah guru berdampak peningkatan efektivitas pembelajaran. Oleh karena itu untuk meningkatkan efektivitas pembelajaran, kepala sekolah harus melakukan perbaikan-perbaikan dalam meningkatkan budaya sekolah guru.

Terdapat hubungan positif yang sangat signifikan antara supervisi kepala sekolah dan budaya sekolah secara bersama-sama dengan efektivitas pembelajaran. Oleh karena itu untuk meningkatkan efektivitas pembelajaran, kepala sekolah harus melakukan perbaikanperbaikan dalam melakukan supervisi kepala sekolah dan meningkatkan budaya sekolah.

\section{DAFTAR PUSTAKA}

Adi Kurnia \& Qomaruzzaman, Bambang. 2012. Membangun Budaya Sekolah. Bandung: Simbiosa Rekatama Media.

Dadang Suhardan, 2010. Supervisi Profesional, Bandung : Alfabeta.

E. Mulyasa, 2003. Standar Kompetensi dan Sertifikasi Guru, Bandung: PT. Remaja Rosdakarya.

Luthans, Fred. Organizational Behavior, New York: McGraw-Hill Irwin, 2011

Ipong Dekawati. 2011. Manajemen Pengembangan Guru Profesional Suatu Tinjauan Teoritis dan Empirik, Bandung: Rizqi Press. 
J. Jones and Donald L. Walters, 2008. Human Reasource Management in Education, Manajemen Sumber Daya Manusia dalam Pendidikan, Yogyakarta: Q-Media.

Muhamin, 2010. Manajemen Pendidikan Dalam Penyusunan Rencana Pengembangan Sekolah Madrasah, Jakarta: Kencana

Patric Rahabav, 2016. The Learning Effectiveness Of Akademic Supervisor for Teacher. Journal of Education and Practice: Vol. 7 No. 9. FKIP Unpati Ambon.

Piet A. Sahertian, 2008. Konsep Dasar \& Teknik Supervisi Pendidikan: dalam Rangka Pengembangan Sumber Daya Manusia, Jakarta : Rineka Cipta

Popham, W. James., and Eva L. Baker. 2011. Teknik Mengajar Secara Sistematis Terjemahan Amirul Hadi, Bandung: PT Rineka Cipta.

Popi Sopiatin. 2010. Manajemen Belajar Berbasis Kepuasan Siswa, Jakarta: Ghalia Indonesia.

Byars, Lllyod L dan Rue, Leslie W. 2007. Human Resource Management, 8 edition, MCGraw-Hill, Irwin.

Roseline U. Chidobi (2015) dengan judul Supervision As a Key for Effectiveness Teaching and Learning in Enugu State of Nigeria Secondary School: Relevance and Chellenges, Sciente Research Journal: Vol. III Issue VI, Enugu State University Of Science and Technology Enugu, Nigeria.

Sergiovanni, T.J. \& Starratt, R.J. 2009. Supervision: Human Perspectives, Second Edition, USA: McGraw-Hill Inc. 